\title{
L-CARNITINE SUPPLEMENTATION DECREASES LIPID PEROXIDATION AND IMPROVES CARDIOPULMONARY FUNCTION IN BROILER CHICKENS REARED AT HIGH ALTITUDE
}

\author{
Fariborz KHAJALI $^{*}$ and Zahra KHAJALI ${ }^{2}$ \\ ${ }^{1}$ Department of Animal Science, Shahrekord University, Shahrekord, 88186-34141, Iran; \\ ${ }^{2}$ Shaheed Rajaei Cardiovascular, Medical and Research Center, Vali-Asr Avenue, \\ Tehran, Iran
}

(Received 13 December 2013; accepted 25 June 2014)

\begin{abstract}
An experiment was carried out to examine the effects of L-carnitine supplementation on growth performance and cardiopulmonary function of broiler chickens reared at high altitude (2100 m above sea level). A total of 96 day-old male chicks (Cobb 500) were randomly assigned into two dietary treatments containing 0 (control group) and $200 \mathrm{mg} / \mathrm{kg}$ L-carnitine. The experimental diets were fed for a period of 42 days consisting of the starting (days 1 to 21) and growing periods (days 21 to 42). Nutrient requirements of chickens met the NRC (1994) recommendations. The results showed that dietary L-carnitine had no significant influence on body weight gain, feed intake and feed conversion ratio. L-carnitine reduced plasma concentration of malondialdehyde, packed cell volume (PCV) and abdominal fat deposition compared to the control $(\mathrm{P}<0.05)$. A significant $(\mathrm{P}<$ 0.05 ) decrease was observed in the right to total ventricular weight ratio (RV:TV) in birds receiving L-carnitine when compared to the control. Supplementation of L-carnitine increased plasma nitric oxide and immune responsiveness, which manifested in an increased toe-web thickness index measured at $24 \mathrm{~h}$ following the injection of phytohaemagglutinin P. In conclusion, supplementation of Lcarnitine had beneficial effects on preventing lipid peroxidation and pulmonary hypertension in broiler chickens raised at high altitude.
\end{abstract}

Key words: Amino acid, carnitine, chicken, immunity, pulmonary hypertension

Hypoxia is defined as reduced partial pressure of atmospheric oxygen that occurs with increase in altitude. The partial pressure of oxygen is estimated to drop nearly $0.93 \mathrm{kPa}$ for each $1,000 \mathrm{~m}$ altitude increase (Julian, 2007). In highaltitude regions, broiler chicken producers are confronted with a serious cardiopulmonary disorder named pulmonary hypertension syndrome (PHS; Ascites

*Corresponding author; E-mail: khajali@agr.sku.ac.ir; Phone: 0098 (381) 442-1639; Fax: 0098 (381) 442-4428 
Syndrome). PHS is triggered by hypoxia and manifests itself as accumulation of transudate in the body cavity of fast-growing broilers, which finally causes death (Khajali et al., 2011).

The chemical name of L-carnitine is $\beta$-hydroxy- $\gamma$-N-trimethylaminobutyric acid. This compound has a critical role in the transport of long-chain fatty acids into the mitochondrial matrix for oxidation to provide cellular energy (Arslan, 2006). Therefore, it is involved in the modulation of the cellular and intra-mitochondrial acyl-CoA:CoA ratio (Tanphaichitr and Leelahagul, 1993). Lcarnitine has been reported to enhance myocardial function via improving fatty acid transport into the mitochondria (Ueland et al., 2013). Besides, L-carnitine participates in scavenging reactive oxygen species (Liu et al., 2004) and immunomodulation (Buyse et al., 2007). Erbas et al. (2007) indicated that L-carnitine could increase plasma nitric oxide (NO) in human subjects. Nitric oxide is a potent vasodilator that opposes the onset of PHS in broiler chickens subjected to hypoxia (Khajali and Wideman, 2010).

In most countries, diets of broiler chickens are mainly composed of maize and soybean meal, which have low concentrations of carnitine with limited bioavailability (Arslan, 2006). In the avian body, L-carnitine is synthesised from methionine and lysine in the presence of adequate amounts of iron, ascorbic acid, pyridoxine and niacin (Steiber et al., 2004). In maize-soybean meal diets that are commonly fed to broiler chickens, methionine and lysine are the first- and second-limiting amino acids, respectively (Fernandez et al., 1994), and ascorbic acid supplementation has been shown to be necessary although it is synthesised in the tissues of birds (Attia et al., 2011). Therefore, beneficial effects of L-carnitine supplementation can be expected when diets with marginal levels of methionine and lysine are fed to chickens. It is also worth noting that the requirements for amino acids in broilers grown at high altitude are significantly higher than those published in feeding standards (Basoo et al., 2012). In the present experiment, therefore, L-carnitine was supplemented to a maize-soybean meal diet of broilers exposed to hypobaric hypoxia and the effects of supplementation were studied with respect to pulmonary hypertensive and immune responses.

\section{Materials and methods}

The study was conducted in the experimental facility of Shahrekord University, Shahrekord, Iran, an area located at an altitude of $2,100 \mathrm{~m}$ above sea level. The partial pressure of oxygen is estimated to be $18.95 \mathrm{kPa}$. The experimental animals were kept, maintained and treated according to accepted standards for the humane treatment of animals. The Institutional Animal Care and Use Committee of Shahrekord University approved all procedures used in this study. 
A total of 96 day-old male broilers (Cobb 500) were randomised across 8 floor pens measuring $1.5 \mathrm{~m}^{2}$ (12 birds per pen). Each pen was equipped with a bell drinker and a feed trough. Day-old chicks were allocated to pens so that all pens had equal initial body weights $(455 \mathrm{~g} \pm 10 \mathrm{~g})$. The temperature of the experimental facility was maintained at $32^{\circ} \mathrm{C}$ during week 1 , and set at $25^{\circ} \mathrm{C}$ for week 2 , $20{ }^{\circ} \mathrm{C}$ for week 3 , and $15^{\circ} \mathrm{C}$ thereafter to predispose birds to ascites as previously described (Khajali et al., 2007). Birds were subjected to $23 \mathrm{~h}$ of light and $1 \mathrm{~h}$ of dark throughout the trial. The chickens had free access to feed and water.

Maize- and soybean meal based basal diets were formulated for the starting ( 1 to 3 weeks of age; $\mathrm{AME}=12.55 \mathrm{MJ} / \mathrm{kg} ; \mathrm{CP}=215 \mathrm{~g} / \mathrm{kg}$ ) and growing ( 3 to 6 weeks of age; $\mathrm{AME}=12.95 \mathrm{MJ} / \mathrm{kg} ; \mathrm{CP}=195 \mathrm{~g} / \mathrm{kg}$ ) periods, respectively, and these served as control diets (Table 1). Another treatment was prepared by adding a supplement of L-carnitine (Carniking ${ }^{\circledR}$, Lohmann Co. Ltd., Germany) at $200 \mathrm{mg} / \mathrm{kg}$ to the basal diet at the expense of washed sand.

\section{Table 1}

Composition of the basal diet to which L-carnitine was added for broilers during the starter and grower stages

\begin{tabular}{lcc}
\hline Ingredients (g/kg unless noted) & Starter (days 1 to 21) & Grower (days 21 to 42) \\
\hline Maize & 520 & 597 \\
Soybean meal (44\%) & 388 & 326 \\
Wheat bran & 10 & - \\
Soy oil & 40 & 39 \\
Dicalcium phosphate & 17 & 13 \\
Oyster shell & 14 & 15 \\
Salt & 4 & 3 \\
Vitamin supplement $^{*}$ & 2.5 & 2.5 \\
Trace mineral supplement $^{* *}$ & 2.5 & 2.5 \\
DL-methionine & 1 & - \\
Sand*** & 1 & 2 \\
Metabolisable energy (MJ/kg) & 12.55 & 12.95 \\
Crude protein & 215 & 195 \\
Met + Cys & 8.5 & 7.5 \\
Lys & 11 & 10 \\
Thr & 9.5 & 8.5 \\
Ca & 9.4 & 8.8 \\
Available phosphorus & 4.3 & 3.4 \\
\hline
\end{tabular}

*Provided the following per $\mathrm{kg}$ of diet: vitamin A (trans-retinyl acetate), $3600 \mathrm{IU}$; vitamin $\mathrm{D}_{3}$ (cholecalciferol), $800 \mathrm{IU}$; vitamin $\mathrm{E}$ (DL-tocopheryl acetate), $7.2 \mathrm{mg}$; vitamin $\mathrm{K}_{3}, 1.6 \mathrm{mg}$; vitamin $\mathrm{B}_{1}, 0.72 \mathrm{mg}$; vitamin $\mathrm{B}_{2}, 3.3 \mathrm{mg}$; vitamin $\mathrm{B}_{3}, 0.4 \mathrm{mg}$; vitamin $\mathrm{B}_{6}$, $1.2 \mathrm{mg}$; vitamin $\mathrm{B}_{12}, 0.6 \mathrm{mg}$; folic acid, $0.5 \mathrm{mg}$; choline chloride, $200 \mathrm{mg}$; ${ }^{* *}$ Provided the following per $\mathrm{kg}$ of diet: $\mathrm{Mn}$ (from $\mathrm{MnSO}_{4} \cdot \mathrm{H}_{2} \mathrm{O}$ ), $40 \mathrm{mg}$; $\mathrm{Zn}$ (from $\mathrm{ZnO}$ ), $40 \mathrm{mg}$; $\mathrm{Fe}$ (from $\mathrm{FeSO}_{4} \cdot 7 \mathrm{H} 2 \mathrm{O}$ ), $20 \mathrm{mg} ; \mathrm{Cu}$ (from $\mathrm{CuSO}_{4} \cdot 5 \mathrm{H}_{2} \mathrm{O}$ ), $4 \mathrm{mg}$; I (from $\left.\mathrm{Ca}\left(\mathrm{IO}_{3}\right) 2 \cdot \mathrm{H}_{2} \mathrm{O}\right), 0.64 \mathrm{mg}$; $\mathrm{Se}$ (from sodium selenite), $0.08 \mathrm{mg} ;{ }^{* * *} \mathrm{~L}$-carnitine was replaced for sand to provide the levels of $200 \mathrm{mg} / \mathrm{kg}$ 
Each dietary treatment had four replicates of 12 birds each. Both experimental diets had the same level of calculated metabolisable energy and crude protein and met the requirements for amino acids advocated by the breeder for Cobb 500 chickens (Cobb-Vantress, 2003). All diets were offered ad libitum in mash feed.

At 35 days of age, cutaneous basophil hypersensitivity response to phytohaemagglutinin P (PHA-P) was determined, as an index of a T-cell-induced delayed-type hypersensitivity reaction, according to Corrier and DeLoach (1990). In brief, the feet of 12 birds per treatment were cleaned with $70 \%$ ethanol and the thickness of the toe web between the third and fourth digits was measured using a micrometer. One hundred microlitres of a $100 \mu \mathrm{g} / \mathrm{mL}$ solution of phytohaemagglutinin P (Sigma L-8754, St. Louis, MO) in sterile $0.85 \%$ saline was injected subcutaneously on the left toe web. As a control, $100 \mu \mathrm{L}$ of $0.85 \%$ saline was injected subcutaneously on the right toe web. After 4 and $24 \mathrm{~h}$, the toe webs were cleaned and measured again. The swelling reactions of the toe webs to PHA-P were calculated by the following swelling index: swelling index $=[$ (thickness of left toe web after PHA-P injection - initial thickness of left toe web) - (thickness of right toe web after saline injection - initial thickness of right toe web)].

At 42 days of age, 10 birds per treatment were selected for blood sampling. Blood samples $(3 \mathrm{~mL})$ were collected by heparinised syringes from the brachial vein and centrifuged at $2,500 \times g$ for $10 \mathrm{~min}$ to obtain plasma. Plasma samples were used for the determination of nitric oxide (NO) and malondialdehyde (MDA). Plasma NO (nitrate + nitrite) was measured according to Behrooj et al. (2012). Plasma MDA concentration was determined as an index of lipid peroxidation by the TBA method (Nair and Turner, 1984).

An aliquot of blood was collected in microhaematocrit tubes for measuring haematocrit. Blood smears were also prepared on glass slides to determine the differential leukocyte count. The smears were stained using May-Grünwald and Giemsa stains (Lucas and Jamroz, 1961), approximately 2 to $4 \mathrm{~h}$ after fixation with methyl alcohol. One hundred leukocytes, including granular (heterophils) and nongranular leukocytes (lymphocytes), were counted and the heterophil to lymphocyte ratio (H:L) was calculated. All chemical reagents were obtained from Sigma-Aldrich Co. (Sigma-Aldrich Co., St. Louis, MO, USA).

At 40 days of age, ten chicks were randomly selected from each treatment and electrocardiograms (ECG) were recorded by an automatic instrument (Cardiomax FX-2111, Fukuda, Japan) while standardised at $10 \mathrm{~mm}=1 \mathrm{mV}$ with a chart speed of $50 \mathrm{~mm} / \mathrm{s}$. Lead II was recorded for every chicken, and the amplitude of the T, R and $\mathrm{S}$ waves were recorded.

Body weight gain, feed intake, and feed conversion ratio were obtained during the feeding trial (up to 42 days of age). At the end of trial (day 42), four birds per pen (16 birds per treatment) were euthanised for carcass processing. Data obtained at processing included hot eviscerated skinless carcass weight, 
skinless and boneless breast weight, spleen weight, bursa of Fabricius weight and abdominal fat weight. The hearts were also removed and the ventricles were dissected and weighed to calculate the right-to-total ventricular weight ratio (RV:TV ratio). The RV:TV is indicative of pulmonary hypertension. Right-tototal ventricular weight ratio values higher than 0.25 are considered as pulmonary hypertension (Izadinia et al., 2010; Saedi and Khajali, 2010).

All chicks that died during the experiment were necropsied to determine the cause of death. Nevertheless, mortalities from ascites (RV:TV higher than $0.29)$ were only considered for statistical analysis.

The results were compared by ANOVA using SAS (1997) software in a completely randomised design. When there was sampling within pens, data were subjected to a nested design. The statistical model used for performance data was $\mathrm{Y}_{\mathrm{ij}}=\mu+\mathrm{T}_{\mathrm{i}}+\mathrm{e}_{\mathrm{ij} .}$. For plasma (NO, MDA), blood (haematocrit, $\mathrm{H}: \mathrm{L}$ ), and carcass (carcass yield, breast yield, spleen percentage, bursa percentage, abdominal fat percentage, and RV:TV) data, the model was $Y_{i j k}=\mu+T_{i}+e_{i j}+\varepsilon_{i j k}$. In these models, $Y_{\mathrm{ij}}$ and $\mathrm{Y}_{\mathrm{ijk}}$ are observations; $\mu$ is the general location parameter (i.e. the mean); $\mathrm{T}_{\mathrm{i}}$ is the effect for being in treatment $\mathrm{i}$; $\mathrm{e}_{\mathrm{ij}}$ is the random error; and $\varepsilon_{\mathrm{ijk}}$ is the subsampling error. All physiological data (carcass, blood and plasma) were checked to have a normal distribution and log transformed if necessary. Any data requiring log transformation were back-transformed for the presentation of data. Means were separated by Duncan's multiple range test.

\section{Results}

The immune response of broilers fed different levels of L-carnitine is presented in Table 2. Toe-web thickness index at 4 and $24 \mathrm{~h}$ post injection was higher in birds that received dietary L-carnitine. However, a significant difference was only observed at $24 \mathrm{~h}$ post injection $(\mathrm{P}<0.05)$. The proportions of spleen and bursa to live body weight were not significantly different between the control and L-carnitine supplemented groups.

\section{Table 2}

Effect of dietary L-carnitine on cell-mediated immune response of broiler chickens

\begin{tabular}{llcl}
\hline \multirow{2}{*}{ Variables } & \multicolumn{2}{c}{ L-carnitine $(\mathrm{mg} / \mathrm{kg})$} & \multirow{2}{*}{ SEM } \\
\cline { 2 - 3 } & \multicolumn{1}{c}{0} & 200 & \\
\hline Toe-web index 4 h (mm) measured at 35 days of age ${ }^{*}$ & 0.16 & 0.25 & 0.021 \\
Toe-web index 24 h (mm) measured at 35 days of age & $0.18^{\mathrm{b}}$ & $0.27^{\mathrm{a}}$ & 0.024 \\
Spleen weight ratio (\%) measured at 42 days & 0.14 & 0.14 & 0.010 \\
Bursa weight ratio (\%) measured at 42 days & 0.13 & 0.15 & 0.009 \\
\hline
\end{tabular}

${ }^{a, b}$ Means in the same row with different superscript letters are significantly different $(\mathrm{P}<0.05)$;

${ }^{*}$ Each mean represents values from 12 replicates; ${ }^{* *}$ Each mean represents values from 16 replicates 
Table 3 shows plasma and blood variables measured at the end of the experiment (day 42) in broilers receiving L-carnitine. Plasma concentration of NO was increased in birds that received L-carnitine $(\mathrm{P}<0.05)$. Feeding L-carnitine at $200 \mathrm{mg} / \mathrm{kg}$ caused a significant reduction in plasma MDA. Broilers fed Lcarnitine had significantly lower PCV than did birds fed the control diet $(\mathrm{P}<$ $0.05)$. The heterophil to lymphocyte ratio was not significantly affected by dietary L-carnitine level.

Table 3

Effect of dietary L-carnitine on plasma and blood variables of broiler chickens measured at 42 days of age

\begin{tabular}{lccc}
\hline \multirow{2}{*}{ Variables } & \multicolumn{2}{c}{ L-carnitine $(\mathrm{mg} / \mathrm{kg})$} & \multirow{2}{*}{ SEM } \\
\cline { 2 - 3 } & 0 & 200 & \\
\hline Plasma nitric oxide $(\mu \mathrm{m} / \mathrm{L})$ & $8.95^{\mathrm{b}}$ & $10.8^{\mathrm{a}}$ & \multirow{2}{*}{1.40} \\
Plasma malondialdehyde $(\mu \mathrm{m} / \mathrm{L})$ & $6.00^{\mathrm{a}}$ & $3.65^{\mathrm{b}}$ & 0.36 \\
Packed cell volume $(\mathrm{PCV})$ & $43.5^{\mathrm{a}}$ & $39.0^{\mathrm{b}}$ & 0.87 \\
Heterophil to lymphocyte ratio & 0.61 & 0.59 & 0.38 \\
\hline
\end{tabular}

${ }^{a, b}$ Means in the same row with different superscript letters are significantly different $(\mathrm{P}<0.05)$; Each mean represents values from 10 replicates

The effects of dietary L-carnitine on carcass characteristics of broiler chickens are presented in Table 4. Carcass and breast yields were not significantly influenced by dietary L-carnitine supplementation. Although the proportion of heart to live body weight remained unchanged, the right to total ventricular weight ratio was significantly reduced $(\mathrm{P}<0.05)$ in birds receiving L-carnitine when compared to the control. A significant decline in abdominal fat deposition was also observed in birds that received L-carnitine.

Table 4

Effect of dietary L-carnitine on growth performance and carcass characteristics of broiler chickens measured at 42 days of age

\begin{tabular}{lccc}
\hline \multirow{2}{*}{ Variables } & \multicolumn{2}{c}{ L-carnitine (mg/kg) } & \multirow{2}{*}{ SEM } \\
\cline { 2 - 3 } & \multicolumn{2}{c}{200} & \\
\hline Body weight gain (g/bird) (days 1-42) & 1827 & 1916 & 64.5 \\
Feed consumption (g/bird) (days 1-42) & 4207 & 4026 & 101.5 \\
Feed conversion ratio (days 1-42) & 1.90 & 1.95 & 0.018 \\
Carcass yield (\%) & 66.3 & 65.1 & 1.06 \\
Breast yield (\%) & 35.5 & 36.8 & 0.86 \\
Heart (\%) & 0.56 & 0.57 & 0.019 \\
Right ventricle : total ventricles & $0.29^{\mathrm{a}}$ & $0.22^{\mathrm{b}}$ & 0.02 \\
Abdominal fat (\%) & $2.56^{\mathrm{a}}$ & $1.65^{\mathrm{b}}$ & 0.155 \\
& & & \\
\hline
\end{tabular}

\footnotetext{
${ }^{a, b}$ Means in the same row with different superscript letters are significantly different $(\mathrm{P}<0.05)$; Each mean represents values from 16 replicates
} 
There was a reduction of $\mathrm{S}$ wave amplitude in the L-carnitine group relative to the control, though the difference was not significant (Table 5). No significant difference was found for $\mathrm{R}$ and $\mathrm{T}$ wave amplitudes between the treatments.

\section{Table 5}

Effect of dietary L-carnitine on electrocardiographic wave amplitudes of lead II in broiler chickens measured at 40 days of age

\begin{tabular}{lccc}
\hline \multirow{2}{*}{ Variables } & \multicolumn{2}{c}{ L-carnitine $(\mathrm{mg} / \mathrm{kg})$} & \multirow{2}{*}{ SEM } \\
\cline { 2 - 3 } & 0 & 200 & \\
\hline R wave $(\mathrm{mV})$ & 0.35 & 0.25 & 0.033 \\
S wave $(\mathrm{mV})$ & -0.035 & -0.028 & 0.033 \\
T wave $(\mathrm{mV})$ & 0.14 & 0.14 & 0.025 \\
\hline
\end{tabular}

Each mean represents values from 10 replicates

As shown in Table 6, birds fed an L-carnitine supplement had a lower rate of ascites mortality but the difference between the treatments was not significant.

\section{Table 6}

Effect of dietary L-carnitine on cumulative ascites mortality of broiler chickens reared up to 42 days of age

\begin{tabular}{lccc}
\hline \multirow{2}{*}{ Variables } & \multicolumn{2}{c}{ L-carnitine $(\mathrm{mg} / \mathrm{kg})$} & \multirow{2}{*}{ SEM } \\
\cline { 2 - 3 } & 0 & 200 & \\
\hline Ascites mortality (\%) & 22.5 & 18.5 & 3.65 \\
\hline
\end{tabular}

\section{Discussion}

In general, broiler performance in the present trial was relatively poor when compared to the standard of the chicken breed because of the sustained hypobaric hypoxia incurred by high altitude. Signals from hypoxia and the resulting hypoxaemia prompt the body to produce erythropoietin, which results in polycythaemia (elevated packed cell volume, PCV). Polycythaemia per se increases the viscosity of blood, which in turn augments pulmonary arterial pressure. Beker et al. (2003) evaluated the effects of graded atmospheric $\mathrm{O}_{2}$ concentration $(12,14,16,18$ and $20.6 \%)$ on growth performance and the development of PHS in broiler chickens. Their results indicated that birds exposed to $12,14,16,18$ and $20.6 \% \mathrm{O}_{2}$ concentrations weighed $138,287,353,356$ and $371 \mathrm{~g}$ at 14 days of age, respectively, with respective PCV values of 49, 42, 36, 33 and 32. Additionally, reductions in atmospheric $\mathrm{O}_{2}$ availability effectively induced PHS in birds. In the present study, atmospheric $\mathrm{O}_{2}$ concentration was estimated to be $16 \%$. 
The toe-web thickness index reflects the change of cellular immunity in chicken (Corrier and DeLoach, 1990). In our study, the toe-web thickness $24 \mathrm{~h}$ post injection revealed significantly higher values in the L-carnitine group than in the control. This observation implies augmented cell-mediated immunity in chickens fed L-carnitine as compared to those fed the control diet, which reflects an immunomodulatory effect of L-carnitine.

Plasma NO showed an increase due to L-carnitine supplementation. In line with this finding, Erbas et al. (2007) reported that L-carnitine increased NO through reducing the activity of arginase and elevating that of NO synthase. Another study reported by Sharifi et al. (2009) indicated that L-carnitine reduced the activity of angiotensin-converting enzyme in the aorta, heart and kidney in rats, which resulted in higher NO production. It is well documented that diminished NO production has been implicated in the pathogenesis of pulmonary hypertension in humans (Shaul, 2002). Available data suggest that the reduction of NO synthesis in the pulmonary arterioles is also associated with increased pulmonary vasomotor tone, vascular remodelling and impaired heart function in hypertensive broiler chickens (Tan et al., 2007; Khajali et al., 2014). Enhanced NO production can justify a significant decline in RV:TV observed in birds fed Lcarnitine, and reflects an improved pulmonary hypertensive response.

Reducing the effect of MDA accounts for the antioxidative role of Lcarnitine. MDA is a marker of oxidative stress and indicates the degree of lipid peroxidation. This finding suggests the antioxidative role of L-carnitine as a scavenger of reactive oxygen species (ROS). Reactive oxygen species cause damage to cell membranes. Previous reports (Tan et al., 2008; Yousefi et al., 2013) further support this observation. Tan et al. (2008) indicated that addition of a $100 \mathrm{mg} / \mathrm{kg}$ L-carnitine supplement to the diet resulted in significantly lower plasma MDA in broiler chickens. Yousefi et al. (2013) demonstrated that plasma MDA concentration was significantly decreased by dietary supplementation of L-carnitine ranging from 50 to $150 \mathrm{mg} / \mathrm{kg}$ of diet in broiler chickens. Inhibition of ROS generation or scavenging of ROS has been shown to inhibit the hypoxiainduced proliferation in the pulmonary vasculature and, consequently, pulmonary hypertension (Springer et al., 2000).

A significant decline in PCV was observed in chickens fed L-carnitine, which is in agreement with the findings of Geng et al. (2007). It is not clear how L-carnitine could reduce PCV. Nevertheless, this observation can further explain the significant reduction observed in RV:TV in birds receiving L-carnitine. The ratio of heterophils to lymphocytes $(\mathrm{H}: \mathrm{L})$ is an index of stress in chicken (Khajali et al., 2008). There was, however, no significant difference among the treatments for $\mathrm{H}: \mathrm{L}$.

There was no significant change in carcass, breast and heart yields between groups receiving the L-carnitine-supplemented diets and the control group. In harmony with our findings, in a review of the literature Arslan (2006) reported 
that carcass and breast yields were not significantly affected by dietary Lcarnitine supplementation. The RV:TV ratio, however, declined significantly when L-carnitine was administered. The RV:TV ratio is indicative of increased pulmonary arterial pressure. This finding elucidates the beneficial effect of Lcarnitine in improving the cardiopulmonary function of broiler chickens. The significant decline found by us in abdominal fat deposition was consistent with previous results (Rabie and Szilagyi, 1998). Abdominal fat deposition is undesirable for processors because of waste disposal problems. From the nutritional point of view, it is also unpleasant for consumers who are increasingly concerned about the health aspects of their food. In this regard, the fat-reducing effect of Lcarnitine supplementation is an advantage in commercial broiler production. The fat-reducing effect of L-carnitine is attributed to the formation of acylcarnitines that enables the transfer of activated acyl groups into the matrix of mitochondria via the carnitine-acylcarnitine translocase located within the mitochondrial inner membrane in order to enter the $\beta$-oxidation process (Arslan, 2006).

The electrocardiogram wave amplitudes and mortality from PHS were not affected by L-carnitine in the present study.

In conclusion, reduced PCV, plasma MDA concentration and RV:TV and increased plasma NO production in birds receiving L-carnitine may result in a lower rate of PHS mortality in birds fed L-carnitine. L-carnitine supplementation can have beneficial effects on preventing lipid peroxidation and pulmonary hypertension in broiler chickens reared at high altitude.

\section{Acknowledgements}

This project was funded by Shahrekord University of Iran. The authors thank Azam Yousefi for her technical help.

\section{References}

Arslan, C. (2006): L-Carnitine and its use as a feed additive in poultry feeding: a review. Rev. Méd. Vét. 157, 134-142.

Attia, Y., Hassan, A., Tag El-Din, R. A. and Abou-Shehema, B. M. (2011): Effect of ascorbic acid or increasing metabolizable energy level with or without supplementation of some essential amino acids on productive and physiological traits of slow-growing chicks exposed to chronic heat stress. J. Anim. Physiol. Anim. Nutr. 95, 744-755.

Basoo, H., Khajali, F., Asadi Khoshoui, E., Faraji, M. and Wideman, R. F. (2012): Re-evaluation of arginine requirements for broilers exposed to hypobaric condition during the 3- to 6week period. J. Poult. Sci. 49, 303-307.

Behrooj, N., Khajali, F. and Hassanpour, H. (2012): Feeding reduced-protein diets to broilers subjected to hypobaric hypoxia is associated with the development of pulmonary hypertension syndrome. Brit. Poult. Sci. 53, 658-664.

Beker, A., Vanhooser, S. L., Swartzlander, J. H. and Teeter, R. G. (2003): Graded atmospheric oxygen level effects on performance and ascites incidence in broilers. Poult. Sci. 82, 1550-1553. 
Buyse, J., Swennen, Q., Niewold, T. A., Klasing, K. C., Janssens, G. P. J., Baumgartner, M. and Goddeeris, B. M. (2007): Dietary L-carnitine supplementation enhances the lipopolysaccharide-induced acute phase protein response in broiler chickens. Vet. Immunol. Immunopath. 118, 154-159.

Cobb-Vantress (2003): Cobb Broiler Nutrition Guide. Cobb-Vantress, Siloam Springs, AR 72761, United States, 2003.

Corrier, D. E. and DeLoach, J. R. (1990): Evaluation of cell-mediated, cutaneous basophil hypersensitivity in young chickens by an interdigital skin test. Poult. Sci. 69, 403-408.

Erbas, H., Aydogdu, N., Usta, U. and Erten, O. (2007): Protective role of carnitine in breast cancer via decreasing arginase activity and increasing nitric oxide. Cell Biol. Int. 31, 1414-1419.

Fernandez, S. R., Aoyagi, S., Han, Y., Parsons, C. M. and Baker, D. H. (1994): Limiting order of amino acids in corn and soybean meal for growth of the chick. Poult. Sci. 73, 1887-1896.

Geng, A., Li, B. and Guo, Y. (2007): Effects of dietary L-carnitine and coenzyme $\mathrm{Q}_{10}$ at different supplemental ages on growth performance and some immune response in ascitessusceptible broilers. Arch. Anim. Nutr. 61, 50-60.

Izadinia, M., Nobakht, M., Khajali, F., Faraji, M., Zamani, F., Qujeq, D. and Karimi, I. (2010): Pulmonary hypertension and ascites as affected by dietary protein source in broiler chickens reared in cool temperature at high altitudes. Anim. Feed Sci. Tech. 155, 194-200.

Julian, R. J. (2007): The response of heart and pulmonary arteries to hypoxia, pressure and volume. A short review. Poult. Sci. 86, 1006-1011.

Khajali, F. and Wideman, R. F. (2010): Dietary arginine: Metabolic, environmental, immunological, and physiological interrelationships. World's Poult. Sci. J. 66, 751-766.

Khajali, F., Heydary Moghaddam, M. and Hassanpour, H. (2014): An L-arginine supplement improves broiler hypertensive response and gut function in broiler chickens reared at high altitude. Int. J. Biometeorol. 58, 1175-1179.

Khajali, F., Karimi, S. and Qujeq, D. (2008): Probiotics in drinking water alleviate stress of induced molting in feed-deprived laying hens. Asian-Aust. J. Anim. Sci. 21, 1196-1200.

Khajali, F., Liyanage, R. and Wideman, R. F. (2011): Methylglyoxal and pulmonary hypertension in broiler chickens. Poult. Sci. 90, 1287-1294.

Khajali, F., Zamani Moghaddam, A. K. and Asadi Khoshoie, E. (2007): Application of an early skip-a-day feed restriction on blood parameters, carcass traits and development of ascites in broilers reared under regular or cold temperatures at high altitude. Anim. Sci. J. 78, 159-163.

Liu, J., Head, E., Kuratsune, H., Cotman, C. W. and Ames, B. N. (2004): Comparison of the effects of L-carnitine and acetyl-L-carnitine on carnitine levels, ambulatory activity, and oxidative stress biomarkers in the brain of old rats. Ann. New York Acad. Sci. 1033, 117-131.

Lucas, A. M. and Jamroz, C. (1961): Atlas of Avian Hematology. Agriculture Monograph 25. US Department of Agriculture, Washington, D.C.

Nair, V. and Turner, G. A. (1984): The thiobarbituric acid test for lipid peroxidation: structure of the adduct with malondialdehyde. Lipids 19, 804-805.

Rabie, M. H. and Szilagyi, M. (1998): Effects of L-carnitine supplementation of diets differing in energy levels on performance, abdominal fat content, and yield and composition of edible meat of broilers. Brit. J. Nutr. 80, 391-400.

Saedi, M. and Khajali, F. (2010): Blood gas values and pulmonary hypertension as affected by dietary sodium source in broiler chickens reared at cool temperature in a high altitude area. Acta Vet. Hung. 58, 379-388.

Sharifi, A. M., Zare, B., Keshavarz, M. and Ghaderpanahi, M. (2009): Effect of short term treatment of L-carnitine on tissue ACE activity in streptozotocin-induced diabetic rats. Pathophysiology 16, 53-56.

Shaul, P. W. (2002): Regulation of endothelial nitric oxide synthase: Location. Ann. Rev. Physiol. 64, 749-774. 
Springer, J., Juricko, J., Braun-Dullaeus, R. C., Fischer, A. and Kummer, W. (2000): Hypoxia induces proliferation in the pulmonary vascular bed in vitro. Am. J. Respir. Crit. Care Med. 161, A422-A428.

Steiber, A., Kerner, J. and Hoppel, C. L. (2004): Carnitine: a nutritional, biosynthetic, and functional perspective. Mol. Asp. Med. 25, 455-473.

Tan, X., Hu, S. H. and Wang, X. L. (2007): Possible role of nitric oxide in the pathogenesis of pulmonary hypertension in broilers: A synopsis. Avian Path. 36, 261-267.

Tan, X., Hu, S. H. and Wang, X. L. (2008): The effect of dietary L-carnitine supplementation on pulmonary hypertension syndrome mortality in broilers exposed to low temperatures. J. Anim. Physiol. Anim. Nutr. 49, 203-210.

Tanphaichitr, V. and Leelahagul, P. (1993): Carnitine metabolism and human carnitine deficiency. Nutrition 9, 246-254.

Ueland, T., Svardal, A., Oie, E., Askevold, E. T., Nymoen, S. H., Bjørndal, B., Dahl, C. P., Gullestad, L., Berge, R. K. and Aukrust, P. (2013): Disturbed carnitine regulation in chronic heart failure - Increased plasma levels of palmitoyl-carnitine are associated with poor prognosis. Int. J. Cardiol. 167, 1892-1899.

Yousefi, A., Khajali, F., Hassanpour, H. and Khajali, Z. (2013): Dietary L-carnitine improves pulmonary hypertensive response in broiler chickens subjected to hypobaric hypoxia. J. Poult. Sci. 50, 143-149. 